\title{
SURDOS QUE VIVEM NO INTERIOR E A INTERIORIZAÇÃO DA LÍNGUA DE SINAIS: UMA REVISÃO SISTEMÁTICA DE LITERATURA
}

\section{DEAF PEOPLE WHO LIVE IN INNER CITIES AND THE INTERNALIZATION OF SIGN LANGUAGE: A SYSTEMATIC REVIEW}

\author{
Cristiano das Neves Vilela ${ }^{1}$, Anabela Cruz-Santos ${ }^{2}$
}

Submetido em: 23/04/2020

Correções requerida em: 05/06/2020

Aprovado em: 14/09/2020

\section{RESUMO}

Os surdos que vivem no interior passam por muitos desafios específicos que são distintos daqueles enfrentados pelos seus pares nas grandes cidades. O objetivo desse trabalho é fazer uma revisão sistemática de literatura referente aos surdos que usam língua de sinais e vivem nas pequenas cidades do interior, procurando analisar os desafios peculiares que as pessoas surdas que vivem nessas cidades enfrentam quanto a sua escolarização, o acesso e a qualidade dos serviços oferecidos. Nessa revisão, analisamos 8 artigos científicos disponíveis online, enquadrados em qualquer tipo de abordagem metodológica, publicados entre 2000 a 2020 em inglês e português, nas bases de dados da Web of Science, Scopus; SciELO e Google Scholar. Definimos um protocolo de revisão que orientou todo o processo de identificação, avaliação, inclusão e análise dos textos. Na fase de identificação encontramos 171 artigos nas bases de dados. Na fase de avaliação e categorização excluímos os artigos repetidos e fora do escopo e após análise dos resumos excluímos os artigos que possuíam objetivo, participantes e lócus diferente do estabelecido no protocolo, chegando a 89 artigos. Ao aplicar os critérios finais de inclusão e exclusão do protocolo, o número de artigos foi reduzido a 12. Por fim, os 12 artigos foram submetidos aos critérios de elegibilidade final com a leitura completa do texto e 8 artigos foram selecionados para esta revisão. Concluímos que pesquisas sobre a situação dos surdos que vivem no interior são preocupação de investigadores de diversos países. Que no interior, a educação de surdos ocorre em meio a desafios bastante peculiares e que há um descompasso entre a situação educacional e linguística dos surdos que vivem no interior com seus pares nas grandes cidades.

PALAVRAS-CHAVE: Educação de surdos. Interior. Interiorização. Libras. Surdos.

\section{ABSTRACT}

Deaf people living in small inner cities face many specifics challenges than others deaf people from big cities. This paper presents a systematic review regarding deaf people who use sign language and live in small inner cities, trying to analyze the peculiar challenges that deaf people in these cities face about their schooling, access and quality of the services offered. In this review, we analyzed 8 scientific articles available on the internet, framed in any kind of

\footnotetext{
${ }^{1}$ Doutorando em Estudos da Criança, Especialidade de Educação Especial, CIEd-Instituto de Educação, Universidade do Minho / Professor da Universidade Federal de Alagoas. Correio eletrônico: anabelacruz@gmail.com.

${ }^{2}$ Doutorada em Estudos da Criança, especialização em Educação Especial pela Universidade do Minho. Investigadora integrada do Centro de Investigação em Educação (CIEd). Leciona UC relacionadas com as Necessidades Educativas Especiais, Problemas de Comunicação, e Avaliação desde as idades precoces até à idade escolar. Leciona desde 2000 em cursos de formação de professores de Educação Especial e outros profissionais. Tem coordenado e participado em projetos nacionais e internacionais na área das Perturbações da Linguagem. Principais interesses de investigação: aquisição e desenvolvimento de competências de comunicação em crianças com e sem Necessidades Educativas Especiais, construção e validação de instrumentos de avaliação de linguagem, e estratégias baseadas na investigação para crianças com Perturbações da Comunicação, Deficiência Auditiva e Deficiência Visual. Correio eletrônico: anabelacruz@gmail.com
} 
methodologic approach, published between 2000 to 2020 in English and Portuguese in the following databases: Web of Science, Scopus; SciELO and Google Scholar. We defined a review protocol that guided the entire process of identification, inclusion and analyses of the articles. In the identification phase we found 171 papers in the databases. In the evaluation and categorization phase we excluded papers repeated and outside of the proposed target and after analyzing the abstracts we excluded the articles that according with objectives, participants, and location weren't compatible to the protocol. We followed the protocol criteria selection and obtained 12 articles. Finally, these 12 articles have been analyzed by final eligibility criteria with the complete reading of the text and 8 articles were selected for this review. We concluded that researchers from many countries are searching about the situation of the deaf people that live in small inner cities. Furthermore, this review shows that in the inner cities, deaf education occurs in the middle of peculiars challenges and there's a mismatch between the educational and linguistic situation of the deaf that live in inner city and their peers in the big cities.

KEYWORDS: Deaf education. Inner city. Internalization. Libras. Deaf people. 


\section{INTRODUÇÃO}

Os surdos que vivem no interior enfrentam muitos desafios específicos para construção de sua cidadania e uma melhor qualidade de vida. Mesmo com o reconhecimento político das línguas visuais espaciais e a ascensão do status linguístico dessas línguas em vários países, há uma parcela da comunidade surda que, morando distante dos grandes centros urbanos, possivelmente estão em desvantagens em relação aos seus pares em outras partes no que diz respeito ao acesso à educação e a língua de sinais, além da uma grande incidência de representações sociais negativas sobre os surdos (MEIRA, 2017; VILELA, 2019).

Há uma considerável produção científica sobre os surdos e a língua de sinais ao redor do mundo. No Brasil, a Língua Brasileira de Sinais (Libras) é reconhecida como língua nacional das comunidades surdas desde 2002. Diversos aspectos que dizem respeito aos surdos, a Libras e a educação de pessoas surdas são tratados pela legislação federal e desde 2005 a Libras é ensinada como disciplina obrigatória na formação básica de professores. No campo da investigação cientifica, os estudos linguísticos sobre as línguas de sinais e as questões sócio educacionais das pessoas surdas são temáticas consolidadas nos chamados Estudos Surdos (GESSER, 2009; LACERDA; SANTOS, 2014; PERLIN; STROBEL, 2006; QUADROS; KARNOPP, 2004; SÁ, 2010). Mas, o que dizer sobre a produção científica que trata especificamente do uso e abrangência da língua de sinais nacional pelos surdos do interior e das questões educacionais e sociais relacionada aos surdos do interior?

O texto que apresentamos tem o objetivo de realizar uma revisão sistemática de literatura acerca das questões envolvendo os surdos e a língua de sinais em cidades do interior. O Instituto Brasileiro de Geografia e Estatística (IBGE) define cidade como o distrito sede de um município. No Brasil, os territórios dos estados são divididos por municípios que englobam uma cidade sede e agrupamentos populacionais menores chamados de vilas ou povoados. Geralmente o termo interior referese a cidades que não são a capital ou que não fazem parte das cidades adjacentes à região metropolitana da capital do estado. Também pode referir-se a cidades que estão afastadas do litoral, região onde a maioria das metrópoles e capitais brasileiras estão (IBGE,
2017). As cidades do interior podem, a partir da sua população, ser definidas como pequenas, média e grandes cidades. Em algumas definições tipológicas de municípios, as pequenas cidades do interior são aquelas que possuem menos de cinquenta mil habitantes (IBGE, 2011a). No Brasil, segundo o censo de $2010,73 \%$ dos municípios possuem entre 10 e 20 mil habitantes (IBGE, 2011b). Nem sempre o interior está relacionado a áreas totalmente rurais, pois, mesmo os pequenos e médios municípios interioranos possuem em sua maioria um núcleo urbano central com agrupamento populacional denso circundado por áreas menos povoadas e mais rurais e agrícolas em seu território (IBGE, 2017). A revisão buscará literatura que trata dos surdos que usam uma língua visual-espacial nas pequenas cidades do interior e os desafios peculiares que as pessoas surdas que vivem nessas cidades enfrentam quanto a escolarização, acesso e qualidade dos serviços oferecidos.

A questão principal que norteia essa revisão é: Qual a situação socioeducacional e linguística dos surdos que vivem no interior e há diferenças entre ser surdo, sujeito usuário de língua de modalidade visual-espacial, nas grandes cidades e no interior?

\section{METODOLOGIA}

A revisão sistemática ocorreu em três fases: planejamento, execução e sistematização. O planejamento refere-se ao trabalho anterior à busca de publicações nas bases de dados. Nesta fase, os critérios da metodologia utilizada na revisão, a definição da pergunta norteadora da investigação é definida e os parâmetros de exclusão e inclusão das publicações na revisão são estabelecidos. Para determinar esses itens, elaboramos um protocolo de revisão que possibilitou sintetizar em um documento todas as questões de definição da natureza da investigação e escopo e os procedimentos metodológico a seguir.

A partir do protocolo de revisão, definimos como critérios de seleção de fontes: Artigos científicos publicados em periódicos científicos entre o ano 2000 a 13 de janeiro de 2020, com textos integrais disponíveis online e indexados em bases de dados científicas de alta relevância. As línguas dos estudos foram definidas como língua portuguesa e inglês. As bases de dados escolhidas foram: Web of Science, Scopus; SciELO 
e Google Scholar. Quanto aos métodos de busca nas bases de dados, as strings escolhidas foram utilizadas para selecionar publicações cuja presença dessas palavras figurassem no título do artigo, no resumo ou nas palavras-chaves. Procedemos com a leitura do resumo para verificar se as strings encontradas pertenciam ao escopo da busca. Como tipo de estudos a incluir na revisão, buscamos estudos primários de qualquer tipo: exploratórios, descritivos e explicativos e com abordagem quantitativa ou qualitativa.

As strings utilizadas nas buscas foram: Deaf $A N D$ rural; deaf $A N D$ inner city; deaf $A N D$ village; sign language AND rural; sign language AND village; sign language AND countryside; surdo $A N D$ rural; surdo $A N D$ interior; Libras $A N D$ interior.

Os critérios para a inclusão e exclusão dos artigos foram assim definidos: Critérios de inclusão: (A) Trabalhos que tratam de questões envolvendo a língua de sinais nacional em regiões de interior; (B) Trabalhos que tratam das pessoas surdas que vivem no interior. Critérios de exclusão: (A) Textos nos quais o interior figura como categoria secundária, ou seja, o interior é apenas o lócus da investigação ou a menção da localização de uma escola no interior não é relevante à investigação. $O$ escopo da pesquisa não trata dos surdos ou da língua de sinais no interior; $(B)$ textos que tratam dos surdos e do interior de forma secundária geralmente com foco em saúde, diagnóstico e reabilitação; (C) textos que tratam dos surdos no interior, mas seu escopo são as línguas de sinais emergentes; (D) textos sem indexação nas bases de dados ou trabalhos sem texto disponibilizado online na integra ou aqueles que não são artigos científicos.

\section{EXECUÇÃO DA REVISÃO}

A fase de execução refere-se a busca e seleção das referências e consistiu nos seguintes passos: (1) identificação das fontes, (2) avaliação e categorização, (3) conferência das referências; (4) inclusão das fontes. Originalmente planejávamos iniciar a busca a partir das strings "deaf" e "surdo". Logo percebemos que essas strings isoladas retornavam dezenas de milhares de referências. Tornou-se necessário afunilar a busca por adicionar outras strings em associação a essas primeiras. Para isso o parâmetro 'AND' foi utilizado, com o objetivo de encontrar mais de uma string na mesma busca, e as aspas (") serviram para buscar por expressões completas, o que no caso de uma string com duas ou mais palavras, evita a encontrar palavras soltas e sem ligação ao sentido pretendido.

Percebemos na busca que algumas strings referentes a categoria 'local' quando utilizadas juntas a string "surdo' ou 'deaf' não retornaram resultado. Decidimos proceder a busca com os sinônimos: "cidades pequenas", "cidadezinhas", "povoados", "vilas", e em inglês "countryside", "backlands", "country town" e "small town". Entretanto, todas também retornaram sem resultado. O resultado da primeira identificação das fontes pode ser observado na tabela abaixo:

\begin{tabular}{|c|c|c|c|}
\hline Google Scholar $(\mathrm{n}=27)$ & Web of Science $(n=76)$ & Scopus $(n=63)$ & SciELO $(n=5)$ \\
\hline deaf AND rural & $\begin{array}{l}\text { deaf AND inner city } \\
\text { deaf AND rural } \\
\text { deaf AND village } \\
\text { sign language AND countryside } \\
\text { sign language AND rural } \\
\text { sign language AND village }\end{array}$ & \begin{tabular}{|l} 
deaf AND inner city \\
deaf AND rural \\
dea AND village \\
sign language AND countryside \\
surdo AND rural \\
sign language AND rural \\
surdo AND interior
\end{tabular} & \begin{tabular}{|l} 
libras AND interior \\
sign language AND rural \\
sign language AND village \\
surdo AND interior \\
surdo AND rural
\end{tabular} \\
\hline
\end{tabular}

Tabela 1. Strings e Resultados por Base de Dados.

Esta primeira consulta retornou o total de 171 artigos científicos que numa primeira análise atendiam aos critérios da revisão. Os artigos encontrados foram submetidos a um cruzamento entre as bases de dados que foram utilizadas usando o gerenciador de referências Mendeley. Encontramos artigos repetidos em bases de dados distintas e ainda outros trabalhos cuja identificação da repetição foi um pouco mais difícil, pois a grafia variava em cada base de dados, o que dificultava a identificação como sendo o mesmo artigo. Também alguns artigos possuíam títulos e resumo em idiomas diferentes, variando de acordo com a base de dados consultada, o que gerou duplicidade. Nesta fase também foram eliminados os artigos que continham as strings utilizadas na busca, mas sem contexto, por exemplo quando se referiam ao 'interior' da escola ou ao “interior' do sujeito surdo. Após essa verificação inicial chegamos ao número de 141 artigos.

Com os 141 textos, passamos a uma segunda avaliação e categorização das fontes encontradas por meio da leitura mais aprofundada do abstract e de trechos do corpo, focando em identificar o objetivo, o público e o lócus. Percebemos que 40 desses textos não poderiam figurar na revisão por não pertencerem ao escopo da busca. Isso porque, nesses trabalhos, os surdos e o interior estavam secundarizados e não consistiam no objeto especifico dessas investigações. Chegamos à quantidade de 101 artigos, que foram 
submetidos avaliação a partir dos critérios de inclusão e exclusão do protocolo de revisão, 93 trabalhos foram excluídos e 8 foram selecionados para esta revisão.

Trabalhos excluídos: Os 93 trabalhos que foram excluídos da revisão são muito reveladores para nossa investigação. A experiência de exclusão desses textos se revelou bastante interessante na construção do estado da arte, pretendemos a partir deste momento mostrar as razões disso e retornaremos com esse tema nas discussões deste trabalho.

Dos trabalhos analisados, detectamos 14 pesquisas que correspondem ao critério de exclusão (D), ou seja, textos sem indexação nas bases de dados ou trabalhos sem texto disponibilizado online na integra ou ainda aqueles que não são artigos científicos. Algumas fontes nesta categoria não correspondem ao protocolo devido a constarem nas bases de dados como artigos publicados em periódicos científicos, quando na realidade tratavam de artigos de opinião, monografias e até trechos de teses, teses completas ou artigos de instituições governamentais. Por exemplo, oito trabalhos apresentados na tabela abaixo, cujos títulos apontam estar dentro do escopo da revisão, não corresponderam aos critérios de seleção de fontes estabelecidos no protocolo de revisão.

\begin{tabular}{lc}
\hline \multicolumn{1}{c}{ Título } & Ano \\
\hline $\begin{array}{l}\text { Professionals' perceptions of hearing-impairment and the rehabilitation of deaf children in rural } \\
\text { areas of Binga District, Zimbabwe }\end{array}$ & 2002 \\
$\begin{array}{l}\text { A collective case study: How regular teachers provide inclusive education for severely and } \\
\text { profoundly deaf students in regular schools in rural New South Wales (Tese de doutorado) }\end{array}$ & 2005 \\
$\begin{array}{l}\text { Reasons for Deaf Students' School-Weariness in Undeveloped Rural Areas and lts Strategies - A } \\
\text { Case Study of Quzhou School for the Deaf }\end{array}$ & 2005 \\
$\begin{array}{l}\text { Broadening our scope: Supporting the need for oral deaf educators in rural communities (Tese de } \\
\text { master) }\end{array}$ & 2011 \\
$\begin{array}{l}\text { Reducing the social isolation of rural deaf Albertans. Alberta Rural Development Network. } \\
\text { (Informativo do governo) }\end{array}$ & 2013 \\
$\begin{array}{l}\text { Rural Parent Perspectives on Itinerant Service Provision for Their Deaf and Hard of Hearing } \\
\text { Children (Tese de master) }\end{array}$ & 2017 \\
$\begin{array}{l}\text { The Relationship Between Rural Novice Teachers of the Deaf and Their Mentors (Tese de master) } \\
\text { Engaging in a Rural Deaf Community of Practice (Tese de doutorado) }\end{array}$ & 2017 \\
\hline
\end{tabular}

Tabela 2. Trabalhos Relacionados com a Temática Excluídos da Revisão.

Dos textos encontrados, 20 artigos foram excluídos pelo critério de exclusão (C). São textos que tratam dos surdos no interior, mas seu escopo são as línguas de sinais emergentes. Zeshan e De Vos (2012) denominam esse tipo de língua de village sign language e as caracterizam por serem línguas utilizadas em várias partes do mundo dentro de comunidades rurais de sinalizantes que usualmente compartilham sua língua entre membros surdos e ouvintes da comunidade possibilitando nessas regiões um alto grau de integração entre indivíduos surdos e não surdos. Alguns termos alternativos para village sign language encontrados na literatura são 'indigenous sign language', 'rural sign language' ou 'emerging sign languages' (ZESHAN; DE VOS, 2012, p.3-5) Na tabela abaixo poderá ver o título de alguns dos textos com essa temática que foram excluídos da revisão.

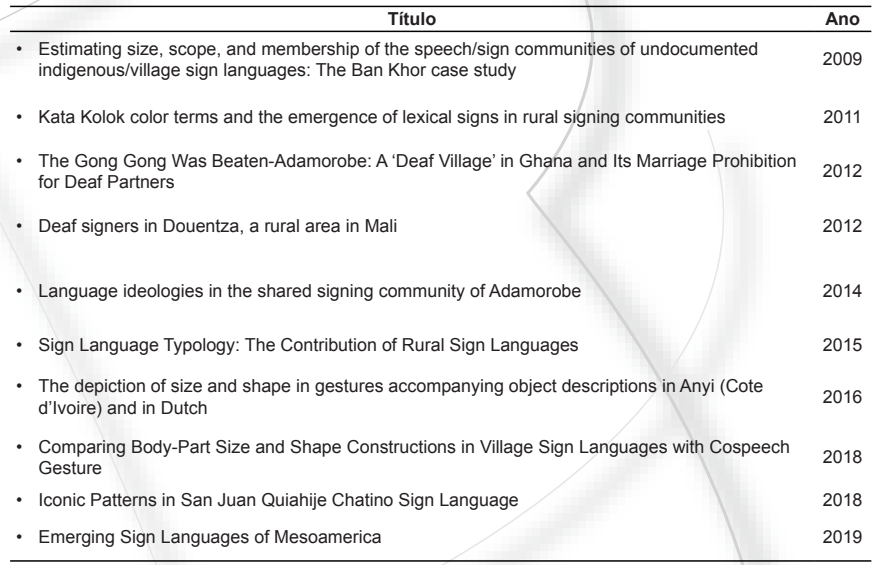

Tabela 3. Artigos Sobre Línguas de Sinais Emergentes Excluídos da Revisão.

É importante notar o grande número de artigos voltados para línguas de sinais emergentes. São pesquisas extremante relevantes ao contribuir para o entendimento de como funciona o processo de aquisição e desenvolvimento de uma língua sinalizada e sua vitalidade. Essas pesquisas podem ainda revelar sobre a língua de sinais nacional. Entretanto, ficamos impressionados que as referências feitas ao interior, quando o escopo da investigação são os surdos ou a língua de sinais nesses espaços rurais, quase sempre estão voltadas às línguas de sinais emergentes e pouco sobre a língua de sinais nacional.

Chegamos à quantidade de 55 trabalhos que tratam dos surdos e do interior, mas foram excluídos de acordo com os critérios (A) e (B). São trabalhos em que o interior é mencionado de forma secundária servindo apenas como o lugar da investigação, como por exemplo, uma escola do interior que tem alunos surdos, mas a investigação não trata das peculiaridades do espaço, ou seja, o escopo da pesquisa não se refere aos surdos do interior ou da língua de sinais no interior. Por fim, obtivemos 12 trabalhos para ser submetidos aos critérios de elegibilidade. Esses textos foram lidos na integra e avaliados quanto aos objetivos da investigação, a 
qualidade metodológica e o os resultados apresentados. Após verificarmos que alguns textos geravam ressalvas quanto a sua adequação aos critérios de elegibilidade definidos no protocolo de revisão, excluímos 4 textos desta revisão. O número total dos trabalhos excluídos está especificado por critério de exclusão de acordo com o protocolo de revisão no gráfico abaixo.

Trabalhos Excluídos ( $n=93$ )

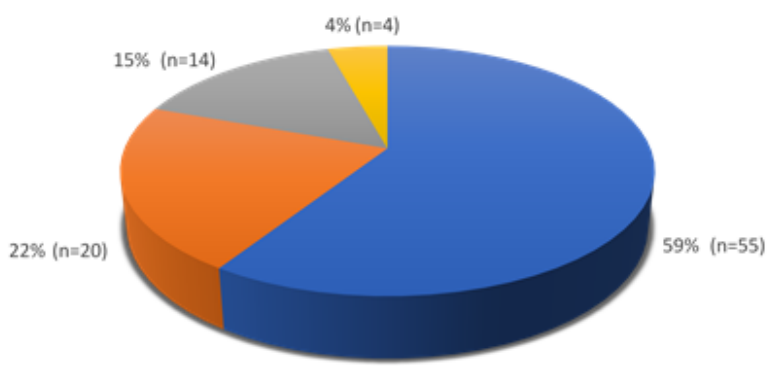

- critérios (A) e (B) = critério (C) = critério (D) = Estudos excuidos após avaliação final

Figura 1. Artigos excluídos da revisão, detalhados por critério de exclusão.

Artigos incluídos na revisão: 08 textos foram selecionados para revisão sistemática. Estes trabalhos obedecem aos critérios de inclusão por tratar das pessoas surdas que vivem no interior e envolvem a língua de sinais nacional nessas regiões. Abaixo a tabela com artigos incluídos na revisão.

\begin{tabular}{|c|c|c|c|}
\hline Id. & Titulo & Objetivo & $\begin{array}{l}\text { Autor, ano, pais de } \\
\text { publicaçăa }\end{array}$ \\
\hline A & $\begin{array}{l}\text { Educational Interpreting: } \\
\text { Understanding the Rural } \\
\text { Experience. }\end{array}$ & $\begin{array}{l}\text { Examinar as experiências, percepçōes e a formação } \\
\text { profissional de interretes de lingua de sinais que } \\
\text { trabalham em escolas de regiōos rurais de dois estados } \\
\text { americanos. A investigação também procurou analisar as } \\
\text { açōes especificas para apoio e preparaçăo profissional de } \\
\text { interpretes em áreas rurais. }\end{array}$ & $\begin{array}{l}\text { Yarger, C. (2001). } \\
\text { USA. }\end{array}$ \\
\hline B & $\begin{array}{l}\text { Deaf and Hearing Impaired } \\
\text { Children in Regional and } \\
\text { Rural Areas: parent Views on } \\
\text { Educational Services. }\end{array}$ & $\begin{array}{l}\text { Investigar as perspectivas dos pais sobre os serviços de } \\
\text { VTOD (Professor Visitante de Surdos) em regiôs rurais } \\
\text { da Austrália Ocidental, bem como identificar aspectos do } \\
\text { serviço VTOD que melhor atendem às necessidades dos } \\
\text { pais e das crianças surdas. }\end{array}$ & $\begin{array}{l}\text { Checker, L., Remine, } \\
\text { M., \& Brown, P. } \\
\text { (2009). AUS. }\end{array}$ \\
\hline c & $\begin{array}{l}\text { Inclusion of deaf students in } \\
\text { mainstream rural primary schools } \\
\text { in Zimbabwe: Challenges and } \\
\text { opportunities. }\end{array}$ & $\begin{array}{l}\text { Identificar os desafios e oportunidades na inclusão } \\
\text { de alunos surdos em escolas primárias seculares e } \\
\text { de administração missionária em uma área rural no } \\
\text { Zimbábue. }\end{array}$ & $\begin{array}{c}\text { Musengi, M., \& } \\
\text { Chireshe, R. (2012). } \\
\text { IND. }\end{array}$ \\
\hline D & $\begin{array}{l}\text { Rural Perspectives of Models, } \\
\text { Services, and Resources } \\
\text { for Students with Hearing } \\
\text { Impairments. }\end{array}$ & $\begin{array}{l}\text { Analisar quais serviços educacionais estão disponiveis } \\
\text { para crianças com deficieiencia auditiva em duas áreas } \\
\text { rurais e duas áreas metropolitanas dos Estados Unidos, } \\
\text { observando os desafios na educação de surdos nas } \\
\text { regiōes rurais. A pergunta de pesquisa central do texto } \\
\text { é: Os serviços oferecidos atualmente aos estudantes } \\
\text { com deficiência auditiva diferem entre as áreas rurais en } \\
\text { metropolitanas? }\end{array}$ & $\begin{array}{l}\text { Macarro, T., Abou- } \\
\text { Rjaily, K., Stoddard, } \\
\text { S., Sandigo, A., } \\
\text { Peterson, P., \& Ross, } \\
\text { V. (2014). USA. }\end{array}$ \\
\hline E & $\begin{array}{l}\text { Language and culture in the deaf } \\
\text { community: a case study in a south } \\
\text { african special school. }\end{array}$ & $\begin{array}{l}\text { Estudo de caso etnográfico realizado numa escola } \\
\text { especial rural da Africa do Sul sobre a cultura dos } \\
\text { surdos, a participacazão destes na comunidade surda e na } \\
\text { comunidade ouvinte e o papel da lingua de sinais para } \\
\text { os surdos rurais. }\end{array}$ & $\begin{array}{l}\text { Stander, M., \& } \\
\text { Mcllroy, G. (2017). } \\
\text { RSA. }\end{array}$ \\
\hline $\mathrm{F}$ & $\begin{array}{l}\text { Monitoring inclusive education in } \\
\text { Chile: iffferences between urban } \\
\text { and rural areas }\end{array}$ & 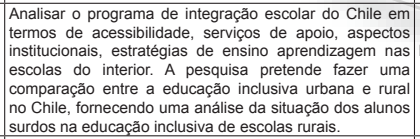 & $\begin{array}{l}\text { Rozas, M., Rebolledo } \\
\text { J., \& Besoain, A. } \\
\text { (2017). UK. }\end{array}$ \\
\hline G & $\begin{array}{l}\text { Unregulated autonomy: } \\
\text { uncredentialed educational } \\
\text { interpreters in rural schools. }\end{array}$ & $\begin{array}{l}\text { Verificar como os interpretes educa } \\
\text { sinais sem credenciamento e sem } \\
\text { a uma avaliação de habili } \\
\text { desempenhavam seu papel em uma }\end{array}$ & $\begin{array}{l}\text { Fitzmaurice, S. } \\
\text { (2017). USA. }\end{array}$ \\
\hline $\mathrm{H}$ & $\begin{array}{l}\text { Deaf people with "no language": } \\
\text { Mobility and flexible accumulation } \\
\text { in languaging practices of deaf } \\
\text { people in Cambodia. }\end{array}$ & \begin{tabular}{|l|} 
Investigação realizada no Camboja que foca nos \\
diferentes recursos comunicativos, além da lígnua de \\
sinais nacional, que os surdos que vivem em lugares \\
distantes das grandes cidades utilizam. O estudo examina \\
como as noçóes de dicotomia urbana / rural desvalorizam \\
as práticas comunicativas de surdos do interior.
\end{tabular} & $\begin{array}{l}\text { Harrelson, E. M. } \\
\text { (2017). DE }\end{array}$ \\
\hline
\end{tabular}

Tabela 5. Artigos Incluídos na Revisão
A figura abaixo sintetiza o fluxograma da execução da revisão e a quantidade de artigos no final de cada fase. A fase de identificação produziu 171 artigos. Após a avaliação e categorização dos trabalhos, o número de artigos ficou em 89. Ao submeter esses trabalhos aos critérios de elegibilidade reduzimos esse número a 12 artigos. Por fim, tivemos como número final, 8 artigos incluídos na revisão.
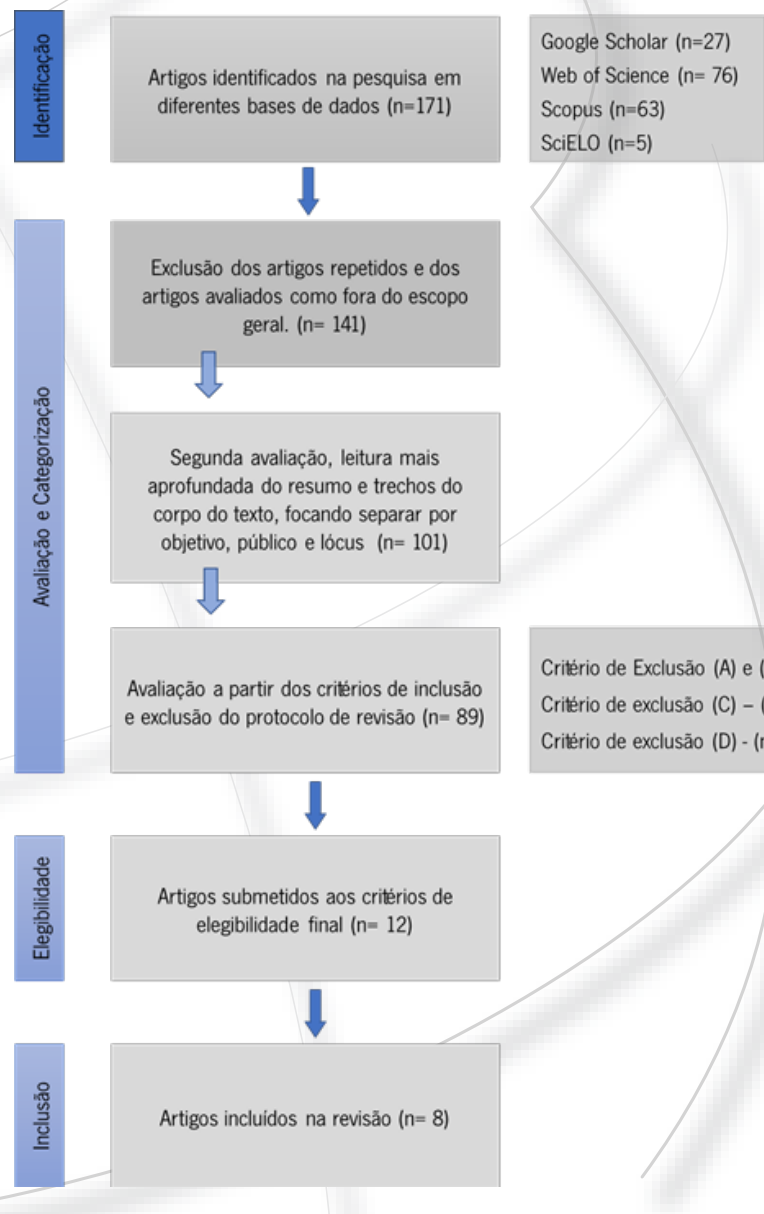

Figura 2. Fluxograma da revisão.

\section{RESULTADOS}

Os 8 artigos elegíveis para a revisão foram analisados independentemente do tipo de investigação ou da metodologia empregada. A leitura procurou examinar aspectos relativos à questão dos surdos no interior sob diversos aspectos e objetivou definir categorias principais sob as quais os estudos sobre as pessoas neste espaço vêm sendo desenvolvidos. Os textos serão apresentados na seguinte sequência: analise das questões metodológicas dos trabalhos, analise da síntese dos dados encontrados, sistematização das 
conclusões encontradas.

Quanto a caracterização metodológica dos trabalhos, há trabalhos do tipo qualitativo e quantitativo e misto. Os instrumentos de coleta de dados foram variados nos diversos tipos de trabalhos, sendo do tipo entrevistas, entrevistas etnográficas, questionários, observação, observação participante e grupos focais. Ressaltamos a preocupação dos pesquisadores ao utilizar instrumentos em língua de sinais ou intérpretes quando os participantes são surdos.

\begin{tabular}{|c|c|c|c|}
\hline $\mathrm{N}$. & $\begin{array}{l}\text { Autor, ano e país de } \\
\text { publicaçâa }\end{array}$ & Metodologia & Participantes \\
\hline A & Yarger, C. (2001). USA. & $\begin{array}{l}\text { Estudos de caráter quantitativo e qualitativo. Como } \\
\text { instrumentos de coleta de dados foi usado os questionários } \\
\text { com questōes sobre preparação, treinamento e suporte para } \\
\text { intérreteses educacionais e entrevistas com perguntas abertas } \\
\text { sobre os desafios e problemas na atuação e sobre formaçăo } \\
\text { necessária. }\end{array}$ & $\begin{array}{l}63 \text { intérpretes } \\
\text { educacionais que } \\
\text { trabalaham em escolas } \\
\text { rurais. }\end{array}$ \\
\hline B & $\begin{array}{l}\text { Checker, L., Remine, M., } \\
\text { \& Brown, P. (2009). AUS. }\end{array}$ & $\begin{array}{l}\text { A investigação foi de caráter qualitativo e quantitativo e } \\
\text { teve como instrumento de coleta de dados foi usado um } \\
\text { questionário de sete páainas com } 36 \text { questōes, sendo } 29 \text { de } \\
\text { mútipla escolha e } 7 \text { perguntas abertas. }\end{array}$ & $\begin{array}{l}34 \text { pais de estudantes } \\
\text { surdos e deficientes } \\
\text { auditivos residentes em } \\
\text { cinco regióes ruaris do } \\
\text { oeste da Austrália. }\end{array}$ \\
\hline C & $\begin{array}{l}\text { Musengi, M., \& Chireshe, } \\
\text { R. (2012). IND. }\end{array}$ & $\begin{array}{l}\text { Estudo de caráter qualitativo realizado por meio de estudo } \\
\text { de caso. Os participantes foram escolhidos por amostra } \\
\text { intencional. Foram utilizadas entrevistas a diretores e } \\
\text { professores da sala regular, grupos focais para entrevistar } \\
\text { os estudantes surdos e observação das aulas em cada uma } \\
\text { das duas escolas. }\end{array}$ & $\begin{array}{l}27 \text { participantes, } \\
\text { sendo } 2 \text { diretores de } \\
\text { escola, } 2 \text { professores } \\
\text { especialistas; } 8 \\
\text { professores de sala } \\
\text { regular } 17 \text { estudantes } \\
\text { surdos. }\end{array}$ \\
\hline D & $\begin{array}{l}\text { Macarro, T., Abou- } \\
\text { Rjaily, K., Stoddard, S., } \\
\text { Sandigo, A., Peterson, P., } \\
\text { \& Ross, V. (2014). USA. }\end{array}$ & $\begin{array}{l}\text { Estudo do tipo qualitativo e quantitativo que utilizou } \\
\text { questionário online em página da internet da Survey Monkey } \\
\text { para obter dados sobre estudantes com deficiência auditiva } \\
\text { em no ensino fundamental e médio, na educação regular } \\
\text { pública, educação especial e escolas particulares. As } \\
\text { primeiras seis questōes tratavam da situacăa demográfica. } \\
\text { A segunda categoria de perguntas, eram do tipo abertas e } \\
\text { travam sobre o trabalho dos participantes com os estudantes } \\
\text { surdos. }\end{array}$ & $\begin{array}{l}30 \text { professores } \\
\text { participantes, sendo } 9 \\
\text { de áreas metropolitanas } \\
\text { e } 21 \text { de regiōes rurais. }\end{array}$ \\
\hline E & $\begin{array}{l}\text { Stander, M., \& Mcllroy, G. } \\
\text { (2017). RSA. }\end{array}$ & $\begin{array}{l}\text { Estudo de caso etnográfico de caráter qualitativo que } \\
\text { utilizou entrevistas, videos gravados e transcriçōes como } \\
\text { instrumentos de coleta de dados. As entrevistas foram } \\
\text { realizadas em SALS (Lingua de Sinais Sul Africana). A } \\
\text { abordagem de análise de conteúdo foi utilizada para analisar } \\
\text { os dados da investigação. }\end{array}$ & $\begin{array}{l}2 \text { alunos surdos do } 12^{\text {a }} \\
\text { ano e três assistentes } \\
\text { de ensino de surdos } \\
\text { da Thiboloha Special } \\
\text { School. }\end{array}$ \\
\hline $\bar{F}$ & $\begin{array}{l}\text { Rozas, M., Rebolledo, J., } \\
\text { \& Besoain, A. (2017). UK. }\end{array}$ & 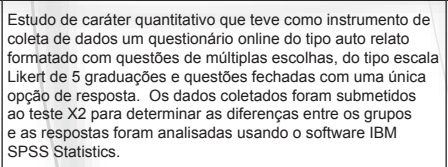 & $\begin{array}{l}\text { Coordenadores do } \\
\text { Programa Chileno de } \\
\text { Integração Escolar (PIE) } \\
\text { de } 356 \text { escolas. }\end{array}$ \\
\hline G & $\begin{array}{l}\text { Fitzmaurice, S. (2017). } \\
\text { USA. }\end{array}$ & $\begin{array}{l}\text { Pesquisa de cunho qualitativo que utilizou entrevistas } \\
\text { etnográficas e observaçãa de campo. As entrevistas iniciais } \\
\text { foram do tipo semiestruturadas. Nas observaçōes de campo, } \\
\text { nos momentos de atuação dos intérpretes, entrevistas } \\
\text { informais foram realizadas. Os videos das entrevistas foram } \\
\text { transcritos para identificar temas emergentes. Fi utilizado } \\
\text { o software NVivo para fazer análise qualitativa dos dados a } \\
\text { partir dos temas emergentes selecionados. }\end{array}$ & $\begin{array}{l}3 \text { interpretes } \\
\text { educacionais sem } \\
\text { qualquer tipo de } \\
\text { licença profissional } \\
\text { ou certificaçăo e que } \\
\text { trabalham em eqcolas } \\
\text { de áreas rurais. }\end{array}$ \\
\hline $\mathrm{H}$ & $\begin{array}{l}\text { Harrelson, E. M. } \\
\text { (2017). DE }\end{array}$ & $\begin{array}{l}\text { Estudo de natureza quantitativa que utilizou de observação } \\
\text { participante e entrevistas como instrumento e técnica de } \\
\text { coleta de dados. Otrabalho de campo durou } 15 \text { meses em } \\
\text { várias partes do Camboja. }\end{array}$ & \begin{tabular}{|l} 
Estudantes surdos \\
de áreas rurais do \\
Camboja, surdos que \\
utilizam os serviços de \\
ONGs que atuam com \\
surdos e os funcionários \\
destas instituiçōes.
\end{tabular} \\
\hline
\end{tabular}

Tabela 6. Trabalhos Incluídos por Descrição da Metodologia.

Percebemos na análise da Tabela 5 que dos trabalhos selecionados, cinco pretendiam analisar a qualidade dos serviços educacionais disponíveis para os surdos em regiões rurais. Dois trabalhos ( $A$ e $G$ ) analisavam a formação dos intérpretes de língua de sinais que atuam no interior dos EUA, inclusive tratando sobre a baixa formação profissional e as disparidades em relação a estrutura profissional e de serviços que os intérpretes que atuam em escolas dos grandes centros urbanos possuem.

Três trabalhos ( $B, D$ e $F$ ) buscam analisar a qualidade dos serviços educacionais ofertados a alunos surdos do interior. A investigação no Chile preocupavase com a educação dos surdos nas escolas do interior fazendo uma comparação entre a educação inclusiva urbana e rural no país. Similarmente, o estudo realizado nos EUA também buscava analisar os serviços educacionais que estavam disponíveis para crianças com deficiência auditiva em áreas rurais e se diferiam das áreas metropolitanas. A pesquisa da Austrália também pretendeu avaliar os serviços do Professor Visitante de Surdos que atende regiões rurais do país. Essas investigações revelam como partindo de diferentes pontos do globo os investigadores estão preocupados com as assimetrias na situação escolar dos surdos que vivem longe grandes centros urbanos.

Por fim, os três últimos estudos $(\mathrm{C}, \mathrm{E} \mathrm{e} \mathrm{H})$ tratam da situação dos surdos, em diferentes lugares no mundo, que vivem em regiões do interior. O estudo no Zimbábue trata da inclusão de surdos nas escolas seculares e religiosas do interior e o papel da língua de sanais e da cultura surda como construtor da identidade dos surdos em áreas rurais e avalia a relação da comunidade escolar com as peculiaridades dos surdos. $\mathrm{Na}$ África do Sul o estudo discute o papel da língua de sinais em regiões afastadas, que é analisado ao se discutir sobre a cultura surda e o envolvimento dos estudantes surdos na comunidade surda e ouvinte. A investigação realizada no Camboja chama a atenção para os diferentes recursos comunicativos, além da língua de sinais nacional, que os surdos em regiões do interior usam, trata também do aprendizado da língua nacional de sinais quando mudam para as capitais e as condições linguísticas dos surdos que vivem no interior.

Quanto aos resultados encontrados, os trabalhos ( $A$ e G) que tratam sobre a formação de intérpretes para atuar em regiões do interior, concluem que intérprete em áreas mais distantes dos grandes centros trabalha em meio a exclusão e isolamento do restante da equipe escolar. Dificuldades financeira, por causa dos baixos salários e falta de apoio profissional impedem participar de workshops e conferências para formação continuada. Os intérpretes sentiram-se ansiosos com a sua situação financeira, situação de saúde e pouca renda vinda da profissão. O estudo mostrou que há falta de informação, compreensão e organização por 
parte da escola e dos órgãos de educação em relação ao atendimento adequado aos alunos surdos nas áreas rurais. Os intérpretes nessas áreas precisavam de mais treinamento e experiência prática e recursos adicionais de trabalho (YARGER, 2001). A investigação que analisou o papel dos intérpretes educacionais sem formação que trabalham em regiões rurais, descobriu que suas experiências eram caracterizadas por uma espécie de autonomia não regulamentada. As consequências são a falta de qualidade na interpretação e precariedade nas relações de trabalho que trazem prejuizo aos estudantes surdos. É necessário a manutenção de um padrão nacional para os intérpretes educacionais pois há um abismo entre os padrões de serviços oferecido nas pequenas cidades e nas metrópoles (FITZMAURICE, 2017).

Os artigos (B, D e F) que analisam a qualidade dos serviços educacionais ofertados a alunos surdos do interior revelaram de forma geral discrepância entre os serviços educacionais providos em regiões mais afastadas e os grandes centros urbanos. Embora os pais aprovem o serviço de VTOD na Austrália, há um reconhecimento de que deve haver mais formação para os professores que atuam nessas áreas e o desenvolvimento de políticas e diretrizes especificas para atender os alunos surdos que moram longe das grandes cidades (CHECKER; REMINE; BROWN, 2009). Nos EUA, os pesquisadores concluíram que há necessidade de mais formação para professores de surdos, há pouca interação familiar com as crianças surdas e pouco envolvimento familiar no processo educacional. A quantidade menor de recursos para escolas do interior e as grandes distâncias tornam difícil vencer dificuldades como as modificações instrucionais, delimitação dos papéis e responsabilidades dos cuidadores, professores e intérpretes e melhorar as habilidades de comunicação dos alunos e com eles (MACARRO et al., 2014). No Chile, a comparação das escolas urbanas e rurais mostra uma lacuna na implementação da inclusão de surdos no interior no que diz respeito a profissionais, materiais, salas de recursos, interpretação da língua de sinais. Menos da metade das escolas tinham profissionais habilitados em língua de sinais e as escolas rurais apresentam mais dificuldades de incluir surdos por meio língua de sinais (ROZAS; REBOLLEDO; BESOAÍN, 2017).

Por fim, os três últimos estudos $(\mathrm{C}, \mathrm{E}$ e H) concluíram que há muitas dificuldades para que os surdos do interior consigam desenvolver sua língua, cultura e identidade e que as escolas, não raro, não conseguem corresponder a essas peculiaridades. O estudo no Zimbábue revelou que os estudantes surdos em áreas rurais se deparam com escassez de recursos materiais e inadequação de recursos humanos nos ambientes educacionais. A ideia da oralização ainda é presente e muitos professores creem que os alunos surdos precisam ser "normalizados" até corresponder ao ideal dos alunos ouvintes. Muitas vezes a falta de competência linguística na língua de sinais por parte da equipe da escola leva a escolha pela oralidade. Mesmo em salas com intérpretes os profissionais não são fluentes, muitas vezes tendo aprendido apenas o alfabeto, numerais e sinais básicos do dia-a-dia que são insuficientes para os conteúdos acadêmicos (MUSENGI; CHIRESHE, 2012). A publicação do Camboja revelou que os surdos que vivem distante dos grandes centros urbanos por vezes são descritos como sem língua, mas eles podem utilizar vários elementos distintos em seu repertório linguístico que são usados em lugares diferentes. É importante ressaltar outras práticas comunicativas que são frequentemente desvalorizadas em comparação com a língua de sinais nacional. A investigação revelou também o papel das grandes cidades em serem o principal lócus da aprendizagem da língua de sinais nacional e como os surdos não fluentes nesta língua e que migram para esses centros se organizam nesse novo contexto (HARRELSON, 2017).

\section{DISCUSSÃO}

Nos artigos analisados encontramos algumas categorias recorrentes relacionadas à questão que norteia esse trabalho, são elas: o interior como espaço peculiar para os surdos; as diferenças entre o espaço o urbano e do interior para as pessoas surdas; desafios para os surdos em áreas distantes dos grandes centros urbanos; a questão da formação de profissionais e o papel da língua de sinais. Essas categorias nos ajudaram a analisar o que encontramos nesta revisão.

Conseguimos perceber no conjunto de textos que analisamos o "interior" como uma categoria que fundamentou a construção dessas pesquisas. Não se trata apenas de investigar questões sobre os surdos, mas das dinâmicas em ser surdo e usar uma língua 
minoritária de modalidade visual-espacial num espaço tradicionalmente mais isolado e carente de serviços do que os grandes centros urbanos. Entretanto, sentimos que nos textos a categoria 'interior' carecia de uma reflexão mais aprofundada. Estão implícitas a construção da categoria nos textos, por exemplo nos trabalhos (B, D e F) quando tratam da comparação entre serviços educacionais para surdos em espaços urbanos e rurais, ou nos textos ( $A$ e $G$ ) que focam nas dificuldades na formação e atuação de profissionais intérpretes de língua de sinais em regiões mais afastadas dos grandes centros urbanos. Os textos apresentados marcam o interior como espaço peculiar de relações muito especificas e distintas para as pessoas surdas. Todavia, quanto ao campo de investigação, embora esse possa ser delimitado pelos objetivos e conclusões dos autores, ainda não está claramente definido como uma área pertencente aos chamados estudos surdos, e, talvez por isso não é fácil para os autores estabelecer o tipo da investigação como um estudo sobre os surdos no interior. Talvez isso possa ser exemplificado se verificarmos a ocorrência da expressão inglesa 'rural' e seus equivalentes nos textos dos artigos e percebermos que ela é menos frequente do que outras, embora o tema central dessas produções é o interior.

A característica mais evidente desses artigos quando tratam dos surdos no interior se referem aos desafios que os surdos enfrentam nesses espaços para construção de sua cidadania como indivíduos pertencentes ao conjunto de cidadãos de uma nação. Todos os textos analisados mostram uma lacuna entre as situações dos surdos na capital e no interior seja na perspectiva educacional, linguísticas ou social.

A formação é atuação dos profissionais que atendem estudantes surdos no interior, sejam eles intérpretes, professores ou outros membros da equipe escolar mostra ser mais difícil e problemática nessas regiões. Várias razões para isso são destacadas nos textos, como a falta de clareza dos pais e dos profissionais sobre os surdos e sua educação, falta de oportunidade; distância dos grandes centros; menos investimento; falta de fiscalização da competência profissional dos intérpretes. Contudo, a questão da falta da língua de sinais como a razão principal entre as diferenças dos níveis encontrados no interior e na capital está evidenciada também na maioria dos artigos. Tanto por parte dos profissionais quanto dos estudantes surdos no interior os baixos níveis de proficiência em língua de sinais são frequentes nos trabalhos. Por exemplo, Harrelson (2017) mostra como os surdos no interior não tem acesso à língua de sinais nacional e que muitas vezes eles são considerados como sem linguagem. Neste texto, o interior é categoria determinada pela falta da língua de sinais nacional e como muitas pessoas imaginam e usando a expressão utilizada no trabalho, o espaço dos surdos "sem linguagem".

Fica evidente a falta de pesquisas que analisam a carência da língua de sinais nacional, no caso do Brasil a Libras, nas regiões mais distantes dos grandes centros urbanos quando percebemos o grande número de trabalhos, entre os que foram excluídos desta revisão, cujo tema se refere as línguas de sinais emergentes. Percebemos que a maioria das pesquisas sobre os surdos que moram em comunidades rurais, comunidades isoladas ou pequenas cidades longe dos grandes centros tratam das línguas de sinais rurais/ emergentes e, de fato, essa tem sido a forma mais usual de abordagem nas investigações sobre linguagem dos surdos nessas regiões. O volume de investigações neste campo é bastante denso em várias partes do mundo. Por outro lado, embora pareça que a situação dos surdos que estão em situação de isolamento nas pequenas cidades é parecida a das comunidades onde se desenvolveram essas línguas de sinais minoritárias, a diferença está na quantidade de surdos que vivem nessas comunidades isoladas, o que permite o desenvolvimento espontâneo de novas línguas. Essa situação de não fazer parte de um território onde floresce uma nova língua de sinais e ao mesmo tempo não ter acesso pleno ao uso e aquisição da língua de sinais nacional, coloca essas pessoas em uma situação distinta daquelas que motivam as pesquisas tradicionalmente feitas com surdos em áreas rurais. De modo que os surdos que estão em situação de isolamento, mas não tem contato pleno com a língua de sinais nacional merecem ser mais amplamente estudados. Ser surdo no interior é uma experiência distinta daquela onde as comunidades surdas existem há décadas ou há mais de um século e ainda mais distinta das comunidades usuárias de línguas de sinais emergentes.

Os textos analisados revelam que, independente da abordagem metodológica escolhida ou do país onde a investigação foi realizada, há recorrência de especificidades no tratar sobre os surdos que vivem no 
interior que apontam para um direcionamento teórico necessário, porém ainda não sistematizado no olhar para este objeto. A ideia é tirar o interior da posição secundária nas investigações sobre os surdos que vivem lá. O número de textos excluídos desta revisão que não estabeleceram a categoria lócus da investigação, ou seja, o interior, como fornecedor de informações e questionamentos, ou seja, como uma categoria a ser explorada, nos leva a crer que para os investigadores, até certo ponto era normal, esperar que os surdos no interior encontrassem mais dificuldades, uma situação linguística e educacional pior do que seus pares nas grandes cidades e que/não teriam acesso à língua de sinais. Desta forma o interior passa a ser uma categoria subutilizada, já que para esse espaço é esperado uma situação pior do que nas capitais. Se fizermos a pergunta: Por que os surdos do interior encontram piores condições de educação e uso de sua língua? A resposta será porque estão no interior. Na realidade o interior é posto como uma resposta quando deveria ser o ponto de partida na análise. Assim, urge o aumento de produção cientifica que foque nas especificidades dos surdos que vivem longe dos grandes centros urbanos.

\section{CONCLUSÃO}

Percebemos que ainda são bastante escassos os textos que tratam de forma aprofundada sobre surdos no interior. A naturalização das condições mais difíceis dos surdos nessas regiões em comparação aos surdos na capital, pode contribuir, em parte, na dificuldade para estabelecer um campo específico de investigação sobre os surdos no interior como parte dos chamados estudos surdos. Entretanto, os textos inseridos na revisão são reveladores de questões importantes e revelam: (1) preocupações com a situação dos surdos em áreas rurais que são comuns a vários países de situações econômica, religiosa e cultural distintas; (2) o interior como o lugar de maior dificuldade para que os surdos alcancem sucesso escolar; (3) um descompasso entre a situação educacional e linguística dos surdos que vivem no interior com seus pares nas grandes cidades, e, por tabela, um descompasso entre a formação e atuação dos professores e profissionais que trabalham com surdos e seus colegas nas grandes cidades.

Percebemos a necessidade de mais investigação sobre esses temas de modo que algumas perguntas possam ser analisadas. Por que as línguas de sinais em algumas regiões não se interiorizaram? Como reduzir as desigualdades na formação de professores e intérpretes que atuam nessas regiões? Como analisar as questões especificas dos surdos que não tem pleno acesso à língua de sinais nacional e diminuir tais assimetrias regionais? Esta revisão ajuda a perceber que mesmo sendo um tema ainda emergente, há questões sobre os surdos no interior que precisam ser aprofundadas por investigadores em várias partes do mundo.

\section{AGRADECIMENTO}

"Este trabalho é financiado pelo CIEd - Centro de Investigação em Educação, Instituto de Educação, Universidade do Minho, projetos UIDB/01661/2020 e UIDP/01661/2020, através de fundos nacionais da FCT/ MCTES-PT."

\section{REFERÊNCIAS}

ADKINS, C. S. Broadening our scope: Supporting the need for oral deaf educators in rural communities. Independent Studies and Capstones. Washington University School of Medicine. 634, 2011. Disponível em: https://digitalcommons.wustl.edu/pacs_capstones/634. Acesso em: 17 fev. 2020.

CAMERON, J. A collective case study: how regular teachers provide inclusive education for severely and profoundly deaf students in regular schools in rural New South Wales. 2005. 543 f. Tese (Doutorado em Educação). University of Newcastle, Newcastle, Austrália. 2005. Disponível em: https://nova.newcastle. edu.au/vital/access/manager/Repository/uon:682. Acesso em: 15 fev. 2020.

CHECKER, L. J.; REMINE, M. D.; BROWN, P. M. Deaf and hearing impaired children in regional and rural areas: parent views on educational services. Deafness \& Education International, v. 11, n. 1, p. 21-38, 2009. DOI: $10.1179 / 146431509790559679$.

DE VOS, Connie. Kata Kolok color terms and the emergence of lexical signs in rural signing communities. The Senses and Society, v. 6, p. 68-76, 2011. DOI: 10. 2752/174589311X12893982233795. 
DE VOS, Connie; PFAU, Roland. Sign language typology: The contribution of rural sign languages. Annual Review of Linguistics, v. 1, p. 265-288, 2015. DOI 10.1146/annurev-linguist-030514-124958.

DUBE, S.; SULLIVAN, K.; WIRZ, S. Professionals' perceptions of hearing-impairment and the rehabilitation of deaf children in rural areas of Binga District, Zimbabwe. African Journal of Special Needs Education, v. 7, n. 1, p. 52-63, 2002.

FITZMAURICE, S. Unregulated Autonomy: uncredentialed Educational Interpreters in Rural Schools. American Annals of the Deaf, v. 162, p. 253 - 264, 2017. DOI: 10.1353/aad.2017.0024.

GESSER, A. Libras? Que língua é essa? Crenças e preconceitos em torno da Língua de Sinais e da realidade surda. São Paulo: Parábola Editorial, 2009.

GOURNARIS, K. Engaging in a rural deaf community of practice. 2019. $164 \mathrm{f}$. Tese (Doutorado em Educação). Portland State University, Portland, USA. 2019. Disponível em https://pdxscholar.library.pdx.edu/ open_access_etds/5114/. Acesso em: 20 fev. 2020.

HARRELSON, E. M. Deaf people with "no language": Mobility and flexible accumulation in languaging practices of deaf people in Cambodia. Applied Linguistics Review, v. 10, n. 1, p. 55-72, 2017. DOI: 10.1515/ applirev-2017-0081.

HOU, L. Iconic patterns in San Juan Quiahije Chatino sign language. Sign Language Studies, v. 18, n. 4, p. 570-611, 2018. DOI: 10.1353/sls.2018.0017.

INSTITUTO BRASILEIRO DE GEOGRAFIA E ESTATÍSTICA (IBGE). Indicadores sociais municipais: uma análise dos resultados do universo do censo demográfico 2010. Rio de Janeiro: IBGE, 2011a.

INSTITUTO BRASILEIRO DE GEOGRAFIA E ESTATÍSTICA (IBGE). Censo Brasileiro de 2010. Rio de Janeiro: IBGE, 2011b.

INSTITUTO BRASILEIRO DE GEOGRAFIA E ESTATÍSTICA (IBGE). Classificação e caracterização dos espaços rurais e urbanos do Brasil: uma primeira aproximação. Rio de Janeiro: IBGE, 2017.

JIANG, L.; ZHOU, Z. Reasons for deaf students' schoolweariness in undeveloped rural areas and its strategies - A case study of Quzhou School for the deaf. Chinese Journal of Special Education, v. 7, n. 16, 2005.

KUSTERS, A. 'The Gong Gong was beaten'-Adamorobe: a 'Deaf Village' in Ghana and Its marriage prohibition for deaf partners. Sustainability, v. 4, n. 10, p. 2765-2784, 2012. DOI: $10.3390 /$ su4102765

KUSTERS, A. Language ideologies in the shared signing community of Adamorobe. Language In Society, v. 43, n. 2, p. 139-158, 2014. DOI: 10.1017/S0047404514000013

LACERDA, C.; SANTOS, L. O ensino de Libras para futuros professores da educação básica. São Carlos: EdUFSCar, 2014.

LARWOOD, L. A promising practice: low incidence teacher education in rural and remote California. Rural Special Education Quarterly, v. 24, n. 3, p. 25-29, 2005. DOI: $10.1177 / 875687050502400304$.

LE GUEN, O. Emerging sign languages of Mesoamerica. Sign Language Studies, v. 19, n. 3, p. 375-409, 2019. DOI: 10.1353/sls.2019.0002.

MACARRO, T.; ABOU-RJAILY, K.; STODDARD, S.; SANDIGO, A.; PETERSON, P.; ROSS, V. Rural perspectives of models, services, and resources for students with hearing impairments. Rural Special Education Quarterly, v. 33, n. 4, p. 24-32, 2014. DOI: $10.1177 / 875687051403300404$.

MEIRA, M. O surdo do contexto rural: desafios e implicações no processo de apropriação da Libras. 2017. 117 f. Dissertação (Mestrado Profissional em Letras) Universidade Estadual de Montes Claros - Unimontes, Montes Claros, 2017.

MUSENGI, M.; CHIRESHE, R. Inclusion of deaf students in mainstream rural primary schools in Zimbabwe: Challenges and opportunities. Studies of Tribes and Tribals, v. 10, n. 2, p. 107-116, 2012. 
NONAKA, A. M. Estimating size, scope, and membership of the speech/sign communities of undocumented indigenous/village sign languages: The Ban Khor case study. Language and Communication, v. 29, n. 3, p. 210-229, 2009. DOI: https://doi.org/10.1016/j. langcom.2009.02.004

NYST, V. The depiction of size and shape in gestures accompanying object descriptions in Anyi (Cote d'Ivoire) and in Dutch (The Netherlands). Gesture, v. 15, n. 2, p. 156-191, 2016. DOI: https://doi.org/10.1016/j. langcom.2009.02.004

NYST, V.; SYLLA, K.; MAGASSOUBA, M. Deaf signers in Douentza, a rural area in Mali. In ZESHAN, U.; DE VOS, C. (Org.). Sign Languages in Village Communities: Anthropological and Linguistic Insights. Boston; Berlin: De Gruyter, 2012. p. 251-276.

PERLIN, G.; STROBEL, K. Fundamentos da educação de surdos. Florianópolis: EDUFSC, 2006.

QUADROS, R. M.; KARNOPP, L. B. Língua de Sinais Brasileira: estudos linguísticos. Porto Alegre: Artmed, 2004.

ROZAS, M.; REBOLLEDO, J.; BESOAÍN, A. Monitoring inclusive education in Chile: Differences between urban and rural areas. International Journal of Educational Development, v. 53, p. 110-116, 2017. DOI: 10.1016/j. ijedudev.2017.01.002.

RUSSELL, D.; DEMKO, R. Reducing the social isolation of rural Deaf Albertans. Alberta Rural Development Network, 2013. Disponível em: http:// wccds.ualberta.ca. Acesso em: 17 fev. 2020.

RYNDA, J. The relationship between rural novice teachers of the deaf and their mentors. 2017. 42 f. Dissertação (Mestrado em Educação Especial). Minot State University, Minot, USA. 2017. Disponível em: https://pqdtopen.proquest.com/doc/1942411380. html?FMT=Al. Acesso em: 18 fev. 2020.

SÁ, N. Cultura, poder e educação de surdos. 2. ed. São Paulo: Paulinas, 2010.
STANDER, M.; MCILROY, G. Language and culture in the Deaf community: a case study in a South African special school. Per linguam - A Journal of Language Learning, v. 33, n. 1, p. 83-98, 2017. DOI: 10.5785/33$1-688$

TANO, A.; NYST, V. Comparing body-part size and shape constructions in village sign languages with cospeech gesture. Sign Language Studies, v. 18. n. 4, p. 517545, 2018. DOI:10.1353/sls.2018.0015.

VILELA, Cristiano. O papel da disciplina Libras frente a representações sociais negativas sobre os surdos em cidades do interior. RIOS (Unirios), v. 21, p. 64, 2019.

WOLF, M. Rural parent perspectives on itinerant service provision for their deaf and hard of hearing children. 2017. 49 f. Dissertação (Mestrado em Educação Especial). Minot State University, Minot, USA. 2017. Disponível em: https://pqdtopen.proquest. com/doc/1972605655.html?FMT=Al. Acesso em: 18 fev. 2020.

YARGER, C. Educational interpreting: understanding the rural experience. American Annals of the Deaf, v. 146, p. 16-30, 2001. DOI: 10.1353/aad.2012.0074.

ZESHAN, U; DE VOS, C. Sign languages in village communities: anthropological and linguistic insights. Berlin: De Gruyter, 2012. 